\title{
Functioning of stroke survivors - A validation of the ICF core set for stroke in Sweden
}

\author{
BEATRIX ALGURÉN ${ }^{1,2}$, ÅSA LUNDGREN-NILSSON ${ }^{3} \&$ \\ KATHARINA STIBRANT SUNNERHAGEN ${ }^{3,4}$
}

${ }^{1}$ School of Health Sciences, Fönköping University, fönköping, Sweden, ${ }^{2}$ Institute of Health and Rehabilitation Science (IHRS), Ludwig-Maximilian University, Munich, Germany, Institute of Neuroscience and Physiology, University of Gothenburg, Göteborg, Sweden, and ${ }^{4}$ Sunnaas Rehabilitation Hospital and Medical Faculty, Oslo University, Oslo, Norway

Accepted July 2009

\begin{abstract}
Purpose. To validate the body functions and activities and participation part of the extended International Classification of Functioning, Disability, and Health (ICF) core set for stroke with a Swedish population in the first 3 months post-stroke. Method. At 6 weeks and at 3 months post-stroke, stroke survivors were evaluated by 59 ICF categories of body functions, 59 categories of activities and participation from the stroke ICF core set (extended version).

Results. The study sample included 99 stroke survivors (54\% women) with an average age of 72 years. Statistical significant problems were identified in 28 ICF categories of body functions and in 41 ICF categories of activities and participation at both time points, at 6 weeks and at 3 months. About $17 \mathrm{ICF}$ categories were reported as problems in independent (i.e. modified Rankin Scale $(\mathrm{mRS}) \leq 2$ ) and about 34 categories in dependent (i.e. $\mathrm{mRS}>2$ ) stroke survivors.

Conclusions. The results suggest a possible reduction of the stroke ICF core set from 59 to 28 categories of body functions and from 59 to 41 categories of activities and participation. Hence, feasibility of the core set for multiprofessional assessment increases and the core set might find more integration in clinical practice. The number of problems in mobility and self-care mainly distinguished between independent and dependent stroke survivors.
\end{abstract}

Keywords: Stroke, functioning, ICF, activities and participation, body functions

\section{Introduction}

Stroke is a leading cause of physical disability worldwide $[1,2]$. There is strong evidence for the effectiveness of comprehensive, multidisciplinary rehabilitation interventions in reducing strokerelated disability $[3,4]$. The efficiency of interprofessional care depends - to some extent - on successful communication of health information across disciplinary boundaries [5]. Incorporating a framework of health and disability, such as the International Classification of Functioning, Disability, and Health (ICF) [6], could optimize multidisciplinary rehabilitation efforts [7]. The ICF has been acknowledged as one possible way to facilitate not only interprofessional communication but also communication between health professionals and patients [8-12]. Furthermore, it has been identified as a possible common framework for consistently reporting functional status (based on a bio-psycho-social perspective) [13-15]. The ICF is, however, difficult to use in a clinical context, as it contains $>1400$ categories.

To improve clinical practicability, ICF core sets have been developed which represent a selection of ICF categories describing the prototypical spectrum of problems in the functioning of patients with specific health conditions [16]. On the basis of evidence gathered from preliminary studies, the core sets were developed in a formal decision-making and consensus-based process for the most burdensome health conditions, including stroke $[17,18]$. The core set for stroke (extended version) includes 59 categories of body functions, 11 categories of body structures, 59 categories of activities and participation and 37 categories of environmental factors, as used in other study [19]. Before this core set can be 
used as a practical tool to guide clinical assessment, there is a need to investigate the degree to which it covers the significant problems of stroke survivors. Hence, the core set for stroke was tested in a crosssectional international multicenter validation study [20]. Given the changing spectrum of problems with increasing time after stroke, however, the core set might also be validated in longitudinal studies. As the recovery process is seen mainly in the first 3 months [21-25], the present study was conducted to investigate differences between the relevance of the core set at two different time points during this period. In addition, the ability to identify independent and dependent stroke survivors was examined. As the primary outcomes of multiprofessional rehabilitation interventions are usually body functions and activities and participation [21,26,27], this study focuses on these two parts of the core set, and the environmental factors are described elsewhere [28].

The two specific aims were: (1) to investigate the frequencies of impairments and limitations of stroke survivors at 6 weeks and 3 months post-stroke reported in the ICF categories included in the core set for stroke (extended version); and (2) to examine the discriminative ability of the identified significant frequent ICF categories in distinguishing between independent and dependent stroke survivors.

\section{Methods}

\section{Participants}

This study included 99 stroke survivors from four stroke units at Sahlgrenska University Hospital, Göteborg. Patients were consecutively recruited from February to July 2006 with the inclusion criteria of a diagnosis of first-ever stroke (ICD-10 codes I60-I67), an age of at least 18 and an ability to give written informed consent (or consent given by next to kin). Stroke was clinically determined by specialists at the stroke units according to the World Health Organization (WHO) criteria [29] and confirmed by computed tomography (CT).

\section{Variables and instruments}

The impairments and limitations of stroke survivors were collected by means of the 59 ICF categories of the component body functions and the 59 categories of the component activities and participation from the Comprehensive ICF core set for stroke (extended version). In the extended version, the comprehensive ICF core set for stroke was amended with categories from the core set for patients with neurological conditions in the acute hospital and in early postacute rehabilitation facilities $[17,30]$. Thus, the core set can be said to be applicable not only in the chronic but also in the early post-stroke phases. All chapters of the body functions (included categories range from b110 to b810) and all chapters of activities and participation (categories range from d110 to d940) are represented by the 118 ICF categories. The qualifier scale proposed by the WHO was used to evaluate the extent of a person's difficulties in each ICF category [6]. The proposed scale has five response categories ranging from 0 to 4 (no/mild/moderate/severe/complete problem). In addition, there are the response options ' 8 - not specified' and ' 9 - not applicable'. The latter is used when a category is not applicable to a particular patient or situation. For example, if someone is retired, the category ' $\mathrm{d} 850$ remunerative employment' is not applicable. The response option ' 8 - not specified' is used when available information is not sufficient to quantify the severity of the problem and/ or is ambiguous (e.g. in interviews with participants with cognitive problems). If the problem is associated with other health conditions than stroke, the option C (for co-morbidity) is selected.

The modified Rankin Scale (mRS) was used to assess global disability. The mRS is a commonly used scale (from ' $0=$ no symptoms at all' to ' $6=$ dead') to describe disability in stroke survivors [31]. The intra-reliability of mRS is good, with a $\kappa$ above 0.80 [32].

\section{Data collection procedures}

A contact person (nurse/physiotherapist) working at each stroke unit informed the research assistant about new admissions on a weekly basis. Eligible stroke patients were seen for recruitment within the first week after admission at baseline. Patients were provided with a written description of the study and in the case of participation written informed consent was obtained. Demographic information, subtype, and side of stroke (both determined by a stroke specialist) were recorded. Participants were followed up at 6 weeks and at 3 months post-stroke either at home or in hospital. Information about participants' health status was gathered from semi-structured questions based on the ICF categories of body functions as well as the categories of activities and participation from the extended stroke core set. After the interview was completed (the duration varied between $30 \mathrm{~min}$ and $2 \mathrm{~h}$ depending on the participant's functioning), the ICF core set was filled in on the basis of the interviewer's observation and the patient's story (in one case supported by the complementing information from the next-of-kin). 
Global stroke severity (mRS) was recorded at recruitment, at 6 weeks and at 3 months post-stroke by the interviewer. The interviews were conducted by the same research assistant, trained within the scope of the international WHO Collaboration Project to validate ICF Core Sets [20]. The study was approved by the Ethics Committee of Göteborg University.

\section{Data analysis}

As the aim of this study was to investigate the frequencies and not the extent of impairments and limitations, the degrees of the qualifier scale were dichotomized as follows: the qualifier 0 (no problem) was maintained, the qualifiers 1 to 4 were recoded to 1 (problem), the response option ' 8 - not specified' was treated as missing, whereas the response option ' 9 - not applicable' was recoded to 0 (no problem). Two subgroups at each time point were generated: independent stroke survivors were defined by scoring 2 or under on the mRS, and those scoring $>2$ were defined as dependent stroke survivors. This was accepted as meaningful dichotomizing with a sensitivity of $85 \%$ and a specificity of $87 \%$ [33]. Univariate statistics were used to describe the sample characteristics and examine the frequencies of impairments and limitations. When the variables were not normally distributed (Kolmogorov-Smirnov test [34]), medians were reported. To investigate differences in the number of problems between independent and dependent stroke survivors, the $U$-test was used. All tests were carried out as twosided at local $\alpha$ levels of $5 \%$. Statistical analyses were performed with SPSS (Version 13.0).

\section{Results}

\section{Study participants}

The 99 participants ( $54 \%$ women) had a mean age of 72 years. Cerebral infarction was the main cause of diagnosed stroke $(81 \%)$. At recruitment, 26 participants were classified as independent (i.e. $m R S \leq 2$ ) and 73 as dependent (i.e. $\mathrm{mRS}>2$ ), at 6 weeks; 16 more participants were independent and at 3 months post-stroke a total of 49 participants were independent and 40 were dependent. About 17 ICF categories were reported as problems in independent and about 34 categories in dependent stroke survivors. The baseline characteristics and diagnoses are shown in Table I, stratified by independent/ dependent stroke survivors; global disability and the number of problems of the study sample are shown in Table II.
Table I. Baseline characteristics of study participants.

\begin{tabular}{|c|c|c|c|}
\hline & \multicolumn{2}{|c|}{ Grade of disability } & \multirow[b]{2}{*}{ Total $(n=99)$} \\
\hline & ID $(n=26)$ & $\mathrm{D}(n=73)$ & \\
\hline Age, mean $( \pm$ STD $)$ & $66( \pm 14.2)$ & $78( \pm 9.5)$ & $72( \pm 13.1)$ \\
\hline \multicolumn{4}{|l|}{ Gender, $n(\%)$} \\
\hline Female & $15(58)$ & $39(53)$ & $54(54)$ \\
\hline Male & $11(42)$ & $34(47)$ & $45(46)$ \\
\hline \multicolumn{4}{|c|}{ Diagnose ICD $10, n(\%)$} \\
\hline I61 & $2(8)$ & $9(12)$ & $11(11)$ \\
\hline I63 & $19(73)$ & $62(85)$ & $81(81)$ \\
\hline I64 & $1(4)$ & $1(1)$ & $2(2)$ \\
\hline Others (I670; I676) & $4(15)$ & - & $4(4)$ \\
\hline \multicolumn{4}{|l|}{ Localization, $n(\%)$} \\
\hline Left & $11(42)$ & $17(23)$ & $28(28)$ \\
\hline Right & $7(27)$ & $22(30)$ & $29(29)$ \\
\hline Bilateral & $1(4)$ & $3(4)$ & $4(4)$ \\
\hline Central & $3(12)$ & $9(12)$ & $12(12)$ \\
\hline Unspecified & $4(15)$ & $22(30)$ & $26(26)$ \\
\hline
\end{tabular}

$\mathrm{ID}$, independent (e.g. $\mathrm{mRS} \leq 2)$; $\mathrm{D}$, dependent (e.g. $\mathrm{mRS}>2$ ).

Table II. Global disability and number of problems of participants.

\begin{tabular}{|c|c|c|}
\hline & 6 weeks & 3 months \\
\hline & $\begin{array}{c}\text { Median } \\
\text { (25-75 percentiles) }\end{array}$ & $\begin{array}{c}\text { Median } \\
\text { (25-75 percentiles) }\end{array}$ \\
\hline \multicolumn{3}{|l|}{$\mathrm{mRS}$} \\
\hline Total & $3(1-4)$ & $2(1-3.5)$ \\
\hline ID & $1(1-2)$ & $1(0-1.3)$ \\
\hline $\mathrm{D}$ & $3(2-4)$ & $3(2-4)$ \\
\hline \multicolumn{3}{|c|}{ Problems in body functions } \\
\hline Total & $13(9-18)$ & $13(8-17)$ \\
\hline ID & $11(8-13)$ & $17(15-21)$ \\
\hline $\mathrm{D}$ & $10(8-13)$ & $16.5(13.25-22)$ \\
\hline \multicolumn{3}{|c|}{ Problems in activities and participation } \\
\hline Total & $9(8-17)$ & $9(3-16)$ \\
\hline ID & $6(3-9)$ & $6(2.5-10)$ \\
\hline $\mathrm{D}$ & $16(11-19)$ & $18(11.25-22.5)$ \\
\hline
\end{tabular}

ID, independent (e.g. $m R S \leq 2)$; $D$, dependent (e.g. $m R S>2$ ); at 6 weeks classified independent $n=42$ and dependent $n=47$, at 3 months classified independent $n=49$ and dependent $n=40$; $n=89$.

\section{Problems in body functions}

Overall, problems at 6 weeks as well as at 3 months were identified as significant (that happened if at least $10 \%$ of participants had problems in a specific ICF category) in 28 of the 59 ICF categories of body functions. There is no obvious difference in frequencies of impairments between the two time points. b130 energy and drive functions, b144 memory functions, b455 exercise tolerance functions, b730 muscle power, b740 muscle endurance functions, and b770 gait pattern functions were the commonest problems and were reported in more than two-thirds of stroke survivors. The impairments reported with the ICF categories of body functions and their 
frequency at 6 weeks and at 3 months are presented in Table III.

\section{Problems in activities and participation}

A total of 41 of the 59 ICF categories of activities and participation was significantly reported (i.e. at least $10 \%$ of participants) as problems at 6 weeks as well as at 3 months. d630 preparing meals, d640 doing housework and $\mathrm{d} 920$ recreation and leisure were reported significantly more often at 3 months than at 6 weeks. The main problems according to frequencies and number of single problems were reported in the chapter $\mathrm{d} 4$ mobility. At least $50 \%$ of stroke survivors presented problems in $\mathrm{d} 220$ undertaking multiple tasks, d440 fine hand use, d450 walking, and d460 moving around in different locations at 6 weeks. At 3 months, these were still the main problems, plus d640 doing housework. The consequences reported for the ICF codes of activities and participation at the two different time points are shown in Table IV.

\section{Independent and dependent stroke survivors}

At 6 weeks, $42 \%$ of participants were independent and $47 \%$ dependent. At this time point, the independent differed significantly from the dependent stroke survivors in the numbers of problems in all chapters except in chapters b4 functions of the cardiovascular, hematological, immunological, and respiratory systems, d2 general tasks and demands, and $\mathrm{d} 6$ domestic life. The latter two were not significantly distinctive at 3 months. At this time

Table III. Problems in ICF terms of body functions 6 weeks and 3 months post-stroke.

\begin{tabular}{|c|c|c|c|c|c|}
\hline \multirow[b]{2}{*}{ ICF code } & \multirow[b]{2}{*}{ ICF category title } & \multicolumn{2}{|c|}{6 weeks $(n=89)$} & \multicolumn{2}{|c|}{3 months $(n=89)$} \\
\hline & & $\%$ & (CI 95) & $\%$ & (CI 95) \\
\hline \multicolumn{6}{|c|}{ Chapter 1. Mental functions } \\
\hline b126 & Temperament and personality functions & 17 & $(8-27)$ & 22 & $(12-31)$ \\
\hline b130 & Energy and drive functions & 72 & $(62-81)$ & 65 & $(55-75)$ \\
\hline b134 & Sleep functions $(c=18 \%)$ & 36 & $(26-46)$ & 34 & $(24-44)$ \\
\hline b140 & Attention functions & 11 & $(5-18)$ & 11 & $(5-18)$ \\
\hline b144 & Memory functions & 66 & $(56-76)$ & 61 & $(50-71)$ \\
\hline b160 & Thought functions & 12 & $(5-18)$ & 7 & $(2-13)$ \\
\hline b164 & High-level cognitive functions & 22 & $(11-32)$ & 20 & $(9-31)$ \\
\hline b172 & Calculation functions & 17 & $(3-31)$ & 7 & $(-8$ to 21$)$ \\
\hline b176 & $\begin{array}{l}\text { Mental functions of sequencing } \\
\text { complex movements }\end{array}$ & 11 & $(4-18)$ & 6 & $(1-12)$ \\
\hline \multicolumn{6}{|c|}{ Chapter 2. Sensory functions and pain } \\
\hline $\mathrm{b} 210$ & Seeing functions $(c=79 \%)$ & 95 & $(90-99)$ & 96 & $(91-100)$ \\
\hline b235 & Vestibular functions & 34 & $(24-44)$ & 30 & $(20-39)$ \\
\hline b240 & $\begin{array}{l}\text { Sensations associated with hearing } \\
\text { and vestibular function }(c=9 \%)\end{array}$ & 19 & $(11-28)$ & 19 & $(11-28)$ \\
\hline b260 & Proprioceptive functions & 29 & $(20-39)$ & 30 & $(21-40)$ \\
\hline b265 & Touch functions & 11 & $(5-18)$ & 10 & $(4-16)$ \\
\hline b280 & Sensation of pain & 23 & $(14-31)$ & 35 & $(25-45)$ \\
\hline \multicolumn{6}{|c|}{ Chapter 4 . Functions of the cardiovascular, hematological, immunological and respiratory systems } \\
\hline b410 & Heart functions $(c=41 \%)$ & 43 & $(33-54)$ & 42 & $(31-52)$ \\
\hline b420 & Blood pressure functions $(c=55 \%)$ & 81 & $(73-89)$ & 76 & $(67-85)$ \\
\hline b455 & Exercise tolerance functions & 94 & $(89-99)$ & 94 & $(89-99)$ \\
\hline \multicolumn{6}{|c|}{ Chapter 5. Functions of the digestive, metabolic and endocrine systems } \\
\hline b525 & Defecation functions & 17 & $(9-25)$ & 17 & $(9-25)$ \\
\hline b530 & Weight maintenance functions & 26 & $(17-35)$ & 19 & $(11-27)$ \\
\hline b540 & General metabolic functions $(c=15 \%)$ & 26 & $(17-35)$ & 32 & $(22-42)$ \\
\hline \multicolumn{6}{|c|}{ Chapter 6 . Genitourinary and reproductive functions } \\
\hline b620 & Urination functions $(c=5 \%)$ & 20 & $(12-29)$ & 16 & $(8-23)$ \\
\hline \multicolumn{6}{|c|}{ Chapter 7. Neuromusculoskeletal and movement-related functions } \\
\hline b730 & Muscle power functions & 71 & $(61-80)$ & 61 & $(50-71)$ \\
\hline b740 & Muscle endurance functions & 77 & $(68-86)$ & 79 & $(70-87)$ \\
\hline b750 & Motor reflex functions & 14 & $(6-21)$ & 10 & $(4-16)$ \\
\hline b755 & Involuntary movement reaction functions & 52 & $(41-62)$ & 54 & $(43-65)$ \\
\hline b760 & Control of voluntary movement functions & 48 & $(38-59)$ & 44 & $(33-54)$ \\
\hline b770 & Gait pattern functions & 73 & $(64-82)$ & 75 & $(66-84)$ \\
\hline
\end{tabular}

$c=$ co-morbidity. 
Table IV. Problems in ICF terms of activities and participation 6 weeks and 3 months post-stroke.

\begin{tabular}{|c|c|c|c|c|c|}
\hline \multirow[b]{2}{*}{ ICF code } & \multirow[b]{2}{*}{ ICF category title } & \multicolumn{2}{|c|}{6 weeks $(n=89)$} & \multicolumn{2}{|c|}{3 months $(n=89)$} \\
\hline & & $\%$ & (CI 95) & $\%$ & (CI 95) \\
\hline \multicolumn{6}{|c|}{ Chapter 1. Learning and applying knowledge } \\
\hline $\mathrm{d} 130$ & Copying & 11 & $(2-19)$ & 8 & $(-1$ to 17$)$ \\
\hline $\mathrm{d} 135$ & Rehearsing & 22 & $(11-34)$ & 11 & $(0-21)$ \\
\hline $\mathrm{d} 155$ & Acquiring skills & 27 & $(17-37)$ & 25 & $(16-35)$ \\
\hline $\mathrm{d} 160$ & Focusing attention & 31 & $(21-41)$ & 30 & $(20-40)$ \\
\hline $\mathrm{d} 166$ & Reading & 40 & $(30-51)$ & 34 & $(24-44)$ \\
\hline $\mathrm{d} 170$ & Writing & 27 & $(18-37)$ & 30 & $(20-39)$ \\
\hline $\mathrm{d} 172$ & Calculating & 12 & $(4-20)$ & 4 & $(-1$ to 9$)$ \\
\hline $\mathrm{d} 175$ & Solving problems & 13 & $(6-21)$ & 9 & $(2-15)$ \\
\hline $\mathrm{d} 177$ & Making decisions & 17 & $(9-25)$ & 14 & $(6-21)$ \\
\hline \multicolumn{6}{|c|}{ Chapter 2. General tasks and demands } \\
\hline $\mathrm{d} 210$ & Undertaking a single task & 27 & $(17-36)$ & 32 & $(22-41)$ \\
\hline $\mathrm{d} 220$ & Undertaking multiple tasks & 58 & $(48-69)$ & 59 & $(48-69)$ \\
\hline $\mathrm{d} 230$ & Carrying out daily routine & 24 & $(14-33)$ & 27 & $(18-36)$ \\
\hline $\mathrm{d} 240$ & Handling stress and other psychological demands & 23 & $(14-32)$ & 21 & $(12-29)$ \\
\hline \multicolumn{6}{|c|}{ Chapter 3. Communication } \\
\hline d310 & Communicating with - receiving - spoken messages & 14 & $(6-21)$ & 3 & $(0-7)$ \\
\hline $\mathrm{d} 315$ & Communicating with - receiving - nonverbal messages & 17 & $(7-27)$ & 6 & $(-2$ to 14$)$ \\
\hline d325 & Communicating with - receiving - written messages & 24 & $(15-33)$ & 9 & $(3-15)$ \\
\hline $\mathrm{d} 330$ & Speaking & 15 & $(7-22)$ & 12 & $(5-19)$ \\
\hline d335 & Producing nonverbal messages & 18 & $(8-29)$ & 9 & $(-1$ to 18$)$ \\
\hline d345 & Writing messages & 29 & $(17-41)$ & 23 & $(10-36)$ \\
\hline d350 & Conversation & 16 & $(8-23)$ & 12 & $(5-19)$ \\
\hline $\mathrm{d} 360$ & Using communication devices and techniques & 18 & $(10-26)$ & 18 & $(10-26)$ \\
\hline \multicolumn{6}{|c|}{ Chapter 4. Mobility } \\
\hline $\mathrm{d} 410$ & Changing basic body position & 36 & $(26-46)$ & 37 & $(27-47)$ \\
\hline $\mathrm{d} 415$ & Maintaining a basic body position & 23 & $(14-31)$ & 36 & $(26-46)$ \\
\hline $\mathrm{d} 420$ & Transferring oneself & 37 & $(27-47)$ & 39 & $(29-50)$ \\
\hline $\mathrm{d} 430$ & Lifting and carrying objects & 44 & $(33-54)$ & 38 & $(28-48)$ \\
\hline $\mathrm{d} 440$ & Fine hand use & 53 & $(42-63)$ & 46 & $(36-57)$ \\
\hline $\mathrm{d} 445$ & Hand and arm use & 37 & $(27-47)$ & 38 & $(28-48)$ \\
\hline $\mathrm{d} 450$ & Walking & 78 & $(71-88)$ & 78 & $(69-86)$ \\
\hline $\mathrm{d} 460$ & Moving around in different locations & 71 & $(61-80)$ & 67 & $(57-77)$ \\
\hline $\mathrm{d} 465$ & Moving around using equipment & 42 & $(31-52)$ & 38 & $(28-48)$ \\
\hline $\mathrm{d} 470$ & Using transportation & 11 & $(5-18)$ & 10 & $(4-16)$ \\
\hline \multicolumn{6}{|c|}{ Chapter 5. Self-care } \\
\hline $\mathrm{d} 510$ & Washing oneself & 33 & $(23-43)$ & 32 & $(22-41)$ \\
\hline $\mathrm{d} 520$ & Caring for body parts & 39 & $(29-50)$ & 33 & $(23-43)$ \\
\hline $\mathrm{d} 530$ & Toileting & 25 & $(16-34)$ & 25 & $(16-34)$ \\
\hline $\mathrm{d} 540$ & Dressing & 35 & $(25-45)$ & 33 & $(23-43)$ \\
\hline $\mathrm{d} 550$ & Eating & 21 & $(13-30)$ & 24 & $(15-33)$ \\
\hline $\mathrm{d} 570$ & Looking after one's health & 9 & $(3-15)$ & 10 & $(4-16)$ \\
\hline \multicolumn{6}{|c|}{ Chapter 6. Domestic life } \\
\hline $\mathrm{d} 620$ & Acquisition of goods and services & 26 & $(17-35)$ & 36 & $(26-46)$ \\
\hline d630 & Preparing meals & 25 & $(16-34)$ & 30 & $(21-40)$ \\
\hline d640 & Doing housework & 29 & $(20-39)$ & 50 & $(39-61)$ \\
\hline \multicolumn{6}{|c|}{ Chapter 9 Community, social and civic life } \\
\hline $\mathrm{d} 920$ & Recreation and leisure & 19 & $(11-28)$ & 39 & $(29-50)$ \\
\hline
\end{tabular}

point, $49 \%$ of participants were independent and $40 \%$ dependent. Overall, at both time points, d4 mobility (mean difference $\left.\left(M_{\text {diff }}\right)=4.8\right)$, d5 self-care $\left(M_{\text {diff }}=2.9\right)$, and b7 neuromusculoskeletal and movement-related functions $\left(M_{\text {diff }}=2.6\right)$ followed by b6 genitourinary and reproductive functions $\left(M_{\text {diff }}=0.3\right)$ and $\mathrm{d} 3$ communication $\left(M_{\text {diff }}=1.6\right)$ were significant with $p<0.000$. Table $\mathrm{V}$ shows the comparison of numbers of problems between independent and dependent stroke survivors at 6 weeks and 3 months.

\section{Discussion}

This study showed that 28 of 59 ICF categories of body functions and 41 of 59 ICF categories of activities and participation were significantly identified as 
Table V. Comparison of number of problems between independent and dependent stroke survivors.

\begin{tabular}{|c|c|c|c|c|c|c|c|c|}
\hline \multirow[b]{2}{*}{ ICF chapters } & \multicolumn{4}{|c|}{6 weeks } & \multicolumn{4}{|c|}{3 months } \\
\hline & Mean & $\mathrm{SD}$ & Mean difference & $p$ & Mean & $\mathrm{SD}$ & $\mathrm{M}_{\mathrm{diff}}$ & $p$ \\
\hline \multicolumn{9}{|l|}{ Body functions } \\
\hline \multicolumn{9}{|c|}{ Mental functions } \\
\hline ID & 2.0 & 1.39 & \multirow[t]{2}{*}{-0.7} & \multirow[t]{2}{*}{0.014} & 1.7 & 1.38 & \multirow[t]{2}{*}{-0.9} & \multirow[t]{2}{*}{0.002} \\
\hline $\mathrm{D}$ & 2.7 & 1.54 & & & 2.6 & 1.46 & & \\
\hline \multicolumn{9}{|c|}{ Sensory functions and pain } \\
\hline ID & 1.8 & 1.13 & \multirow[t]{2}{*}{-0.6} & \multirow[t]{2}{*}{0.010} & 1.9 & 1.08 & \multirow[t]{2}{*}{-0.6} & \multirow[t]{2}{*}{0.005} \\
\hline $\mathrm{D}$ & 2.4 & 1.09 & & & 2.5 & 1.09 & & \\
\hline \multicolumn{9}{|c|}{ Functions of the cardiovascular, hematological, immunological, and respiratory systems } \\
\hline ID & 1.9 & 0.78 & \multirow[t]{2}{*}{-0.3} & \multirow[t]{2}{*}{0.068} & 1.9 & 0.82 & \multirow[t]{2}{*}{-0.5} & \multirow[t]{2}{*}{0.008} \\
\hline $\mathrm{D}$ & 2.2 & 0.70 & & & 2.4 & 0.62 & & \\
\hline \multicolumn{9}{|c|}{ Functions of the digestive, metabolic, and endocrine systems } \\
\hline ID & 0.4 & 0.67 & \multirow[t]{2}{*}{-0.4} & \multirow[t]{2}{*}{0.046} & 0.4 & 0.71 & \multirow[t]{2}{*}{-0.6} & 0.002 \\
\hline $\mathrm{D}$ & 0.8 & 0.93 & & & 1.0 & 1.04 & & \\
\hline Genitourina & reprod & unctio & & & & & & \\
\hline ID & 0.0 & 0.15 & -0.3 & 0.000 & 0.0 & 0.14 & -0.3 & 0.000 \\
\hline $\mathrm{D}$ & 0.4 & 0.49 & & & 0.3 & 0.47 & & \\
\hline Neuromusc & letal anc & ment-r & functions & & & & & \\
\hline ID & 2.0 & 1.75 & -2.5 & 0.000 & 2.0 & 1.72 & -2.6 & 0.000 \\
\hline $\mathrm{D}$ & 4.5 & 1.3 & & & 4.7 & 1.03 & & \\
\hline Activities and & pation & & & & & & & \\
\hline Learning an & ying $\mathrm{kn}$ & & & & & & & \\
\hline ID & 1.2 & 1.34 & -1.1 & 0.003 & 1.1 & 1.59 & -0.7 & 0.007 \\
\hline $\mathrm{D}$ & 2.3 & 1.74 & & & 1.9 & 1.57 & & \\
\hline General task & demanc & & & & & & & \\
\hline ID & 1.4 & 1.04 & 0.2 & 0.289 & 1.2 & 1.15 & -0.3 & 0.233 \\
\hline $\mathrm{D}$ & 1.2 & 1.00 & & & 1.5 & 1.01 & & \\
\hline Communica & & & & & & & & \\
\hline ID & 0.2 & 0.54 & -2.1 & 0.000 & 0.2 & 0.86 & -1.1 & 0.000 \\
\hline $\mathrm{D}$ & 2.3 & 2.40 & & & 1.3 & 1.79 & & \\
\hline Mobility & & & & & & & & \\
\hline ID & 1.9 & 1.89 & -4.5 & 0.000 & 2.0 & 1.85 & -5.1 & 0.000 \\
\hline $\mathrm{D}$ & 6.5 & 2.54 & & & 7.1 & 2.35 & & \\
\hline Self-care & & & & & & & & \\
\hline ID & 0.1 & 0.57 & -2.8 & 0.000 & 0.2 & 0.67 & -3.0 & 0.000 \\
\hline $\mathrm{D}$ & 2.9 & 2.03 & & & 3.2 & 2.08 & & \\
\hline Domestic lif & & & & & & & & \\
\hline ID & 0.7 & 1.13 & -0.1 & 0.788 & 0.9 & 1.05 & -0.5 & 0.061 \\
\hline $\mathrm{D}$ & 0.9 & 1.25 & & & 1.4 & 1.22 & & \\
\hline Community & 1 , and $\mathrm{c}$ & & & & & & & \\
\hline ID & 0.3 & 0.48 & 0.3 & 0.001 & 0.4 & 0.49 & -0.01 & 0.907 \\
\hline $\mathrm{D}$ & 0.1 & 0.25 & & & 0.4 & 0.50 & & \\
\hline
\end{tabular}

ID, independent stroke survivor (i.e. $\mathrm{mRS} \leq 2$ ); $\mathrm{D}$, dependent stroke survivor (i.e. $\mathrm{mRS}>2$ ).

problems in a Swedish stroke population at 6 weeks and 3 months after stroke event. It was possible to distinguish between independent and dependent stroke survivors by the number of problems documented by these ICF categories. Chapters $\mathrm{d} 4$ mobility, d5 self-care, and b7 neuromusculoskeletal and movement-related functions followed by b6 genitourinary and reproductive functions and $\mathrm{d} 3$ communication showed the overall best discriminative ability.

In this study, the comprehensive core set for stroke (extended version) was validated by empirical data. Before discussion of the results and any generalization, the characteristics of the study sample should be closely considered. The study participants are Swedish residents and the results cannot be directly generalized to other cultures and populations. The study sample represents an average stroke unit population with an average age of 72 years. As the data collection was based on an interview process which implies that stroke survivors were able to understand and answer questions in a coherent way, the present identified problems probably reflect the spectrum of problems for persons without severely impaired cognitive functions.

\section{Problems in body functions}

Although the core set was developed to define the typical spectrum of problems in functioning of stroke 
survivors, only 28 of 59 ICF categories of body functions were empirically identified as substantial at 6 weeks and 3 months. Overall, the most frequently reported impairments were seen in chapter b7 neuromusculoskeletal and movement-related functions. These findings were supported by the literature, which describes those impairments as common outcome variables of clinical stroke trials $[26,35,36]$. In particular, there were five impairments with which more than two-thirds of stroke survivors were confronted. The first, b455 exercise tolerance functions, was the impairment which was reported in nearly all stroke survivors. As both this study and others have shown that problems with exercise tolerance functions are extremely common in stroke survivors [37,38], more attention might be paid to assessment of and intervention in aerobic exercise capacity. The following three categories, b740 muscle endurance functions, b770 gait pattern functions and b730 muscle power, were impaired in about three-quarters of participants. They are well-known problems often assessed in clinical stroke research [39]. Just as common as the neuromusculoskeletal impairments was the fifth, b130 energy and drive functions (which in ICF language mean mental functions in physiological and psychological mechanisms). This problem, often referred to in the literature as fatigue, has similar prevalence in other studies and has been identified as an important outcome for functioning of stroke survivors $[40,41]$. Moreover, the high number of single problems in chapter b1 mental functions indicates the complexity of global brain function and cognitive problems. Hence, rehabilitation interventions might focus more on this field with respect to its intricacy.

In terms of the 31 discarded categories, most of them are impairments associated with acute problems in the first week of admission or with severe stroke, for example b110 consciousness functions, b114 orientation functions, and b510 Ingestion functions. In addition, there are certain impairments which may be more frequent in very old persons, like b117 intellectual functions (including dementia), b230 hearing functions, b435 immunological system functions, and b440 respiration functions. As the mean age of the stroke survivors of this study was close to the average age of those who suffer a stroke (about 75 years [42-45]), and as stroke survivors primarily suffer mild to moderate stroke [46,47], as in the present study, it can be assumed that the 28 identified categories cover the spectrum of problems of the main group of stroke survivors.

In order to distinguish between independent and dependent stroke survivors, problems of the chapters b6 genitourinary and reproductive functions (i.e. b620 Urination functions) and b7 neuromusculoskeletal and movement-related functions could be assessed, as they were the most distinctive. Results in the literature support these findings $[23,36,48]$.

\section{Problems in activities and participation}

Forty-one of the 59 ICF categories of activities and participation were identified as substantial reported problems of stroke survivors by the empirical data at 6 weeks and 3 months. The main problem, recognized through the high frequency and high number of single problems, was seen in chapter $\mathrm{d} 7$ mobility, which is in accordance with the literature [26,49-51]. Although limitations in chapter b8 selfcare were also quite common in six different categories, problems in chapter $\mathrm{d} 1$ learning and applying knowledge and chapter $\mathrm{d} 3$ communication were less frequently stated but were seen in many single categories. Hence, problems in self-care were concrete whereas problems in learning and applying knowledge and communication appeared to be more diffuse and complex. In particular, the most frequently reported limitations comprised $\mathrm{d} 450$ walking, d460 moving around in different locations, d440 fine hand use, and d220 undertaking multiple tasks. Although rehabilitation interventions already focus on the first three problems [26,5154], the last one is less often seen as a study outcome. There are studies, however, which differentiate between recovery and compensation, which means in this case stroke patients should avoid attempting multiple tasks and learn to do things step by step $[55,56]$.

As regard the 18 discarded categories, they can be divided into two groups. Categories in the first group might not be as common as supposed, e.g. problems in d110 watching, d115 listening, and d120 other purposeful sensing. In the categories of chapter $\mathrm{d} 7$ interpersonal interactions and relationships, no frequent problems were reported. Rather, family and relationships were facilitators for stroke survivors [28]. Categories of the second group are mainly associated with younger stroke survivors, e.g. d845 acquiring, keeping and terminating a job and d850 remunerative employment. As in general the average age of stroke survivors is close to the age of the study sample, the 41 categories identified might comprise the spectrum of limitation of most of the stroke survivors.

Independent and dependent stroke survivors could be distinguished best by reported problems in chapters $\mathrm{d} 3$ communication, $\mathrm{d} 4$ mobility, and $\mathrm{d} 5$ self-care. There were no differences between limitations of independent and dependent stroke survivors in chapters $\mathrm{d} 2$ general tasks and demands and $\mathrm{d} 6$ domestic life.

Owing to the process of data collection (interview), our study has some points of weakness. First, 
the received information could be biased: on one hand, by the interviewer's specific professional knowledge, as their role and educational background may lead them to adopt different points of view when asking questions. On the other hand, by the interviewer's personal judgment regarding the choice of qualifier. Therefore, for further research, more than one person doing the coding would be preferable. Another bias could arise from the subjective component of the ICF classification within activities and participation. More precisely, the objective equal deficits of two people can be reported differently. For example, a person accustomed to walking quickly is going to report moderate limitations if they are not able to walk as quickly as they were able to do prior to the stroke. Another, less active, person is going to report only mild limitations, although he/she cannot walk as fast as the first person. In order to overcome some of these problems the following steps were taken. First, all interviews were conducted by one person. Second, control questions were asked to evaluate the extent of a problem. Third, during the interview observations of the way participants acted were made. Fourth, for the data analysis, the qualifiers were dichotomized (no problem, problem). These factors can be hypothesized to have reduced the impact of the potential bias and thus increased the reliability of the findings. Moreover, our findings demonstrated no abnormality compared with findings in the literature.

\section{Conclusion}

The 28 ICF categories of body functions and the 41 ICF categories of activities and participation which we identified may represent a meaningful reduction of the extended version of the comprehensive core set for stroke to cover the spectrum of problems of most stroke survivors in Sweden. The practical feasibility of the core set is therefore increased and could become a helpful tool in clinical multiprofessional assessment. Consideration of problems in urinary incontinence, neuromusculoskeletal functions, communication, mobility, and self-care provides the most precise discrimination between independent and dependent stroke survivors. Although functional recovery mainly takes place during the first 3 months after stroke, the number of sustainable problems remains constant between 6 weeks and 3 months, i.e. the extent of the problems changes but the problems themselves seldom disappear. In future, a validation of the core set for young stroke survivors and diagnosis of severe stroke may be appropriate, as some of the discarded categories are apparently associated with these groups.

\section{Acknowledgements}

This research was supported by grants from the Swedish Research Council (VR K2002-27-VX14318-01A), the Wilhelm and Martina Lundgren Foundation, the Swedish Association of Persons with Neurological Disabilities (NHR), the NorrbackaEugenia Foundation, the Foundation of the Swedish Stroke Association, the John and Brit Wennerström Foundation of Neurological Research, Västra Götalands Handicap Committee, the Hjalmar Svensson Foundation, the AFA, Praktikertjänst $\mathrm{AB}$ and the Greta and Einar Asker Foundation.

\section{References}

1. World Health Organization. WHO STEPS stroke manual: the WHO STEPwise approach to stroke surveillance. Geneva: World Health Organization; 2006.

2. Elkins JS, Johnston SC. Thirty-year for deaths from ischemic stroke in the United States. Stroke 2003;34:2109-2112.

3. Stroke Unit Trialists' Collaboration. Organised inpatient (stroke unit) care for stroke. Cochrane Database Syst Rev 2001;(3):CD000197. DOI: 10.1002/14651858.CD000197.

4. Kjellström T, Norrving B, Shatchkute A. Helsinborg Declaration 2006 on European stroke strategies. Cerebrovasc Dis 2007;23:229-241.

5. Giacomini M. Interdisciplinarity in health services research: dreams and nightmares, maladies and remedies. J Health Serv Res Policy 2004;9:177-183.

6. World Health Organization. International Classification of Functioning, Disability and Health: ICF. Geneva: World Health Organization; 2001.

7. Gladman JRF. The International Classification of Functioning, Disability, and Health and its value to rehabilitation and geriatric medicine. J Chin Med Assoc 2008;71:275-278.

8. Rentsch H, Bucher P, Nyffeler I, Wolf C, Hefti H, Fluri E, Wenger U, Wälti C, Boyer I. The implementation of the 'International Classification of Functioning, Disability and Health' (ICF) in daily practice of neurorehabilitation: an interdisciplinary project at the Kantonsspital of Lucerne, Switzerland. Disabil Rehabil 2003;25:411-421.

9. Soberg HL, Finset A, Roise O, Bautz-Holter E. Indentification and comparison of rehabilitation goals after multiple injuries: an ICF analysis of the patients', physiotherapists' and other allied professionals reported goals. J Rehabil Med 2008;40:340-346.

10. Steiner WA, Ryser L, Huber E, Uebelhart D, Aeschlimann A, Stucki G. Use of the ICF model as a clinical problem-solving tool in physical therapy and rehabilitation medicine. Phys Ther 2002;82:1098-1107.

11. Stucki G, Ewert T, Cieza A. Value and application of the ICF in rehabilitation medicine. Disabil Rehabil 2002;24:932-938.

12. Tempest $S$, McIntyre A. Using the ICF to clarify team roles and demonstrate clinical reasoning in stroke rehabilitation. Disabil Rehabil 2006;28:663-667.

13. Iezzoni L, Greenberg M. Capturing and classifying functional status information in administrative databases. Health Care Financ Rev 2003;24:61-76.

14. Mayo NE, Poissant L, Ahmed S, Finch L, Higgins J, Salbach NM, Soicher J, Jaglal S. Incorporating the International Classification of Functioning, Disability, and Health (ICF) into an electronic health record to create indicators of function: proof of concept using the SF-12. J Am Med Inform Assoc 2004;11:514-522. 
15. Uestün T, Chatterji S, Kostanjsek N, Bickenbach J. WHO's ICF and functional status information in health records. Health Care Financ Rev 2003;24:77-88.

16. Cieza A, Ewert T, Uestün B, Kostanjsek N, Stucki G. Development of ICF core sets for patients with chronic conditions. J Rehabil Med 2004;S44:9-S44:11.

17. Ewert T, Grill E, Bartholomeyczik S, Finger M, Mokrusch T, Kostanjsek N, Stucki G. ICF core set for patients with neurological conditions in the acute hospital. Disabil Rehabil 2005;27:367-373.

18. Geyh S, Cieza A, Schouten J, Dickson H, Frommelt P, Omar Z, Kostanjsek N, Ring H, Stucki G. ICF core sets for stroke. J Rehabil Med 2004; (Suppl. 44):135-141.

19. Starrost K, Geyh S, Trautwein A, Grunow J, CeballosBaumann A, Prosiegel M, Stucki G, Cieza A. Interrater reliability of the extended ICF core set for stroke applied by physical therapists. Phys Ther 2008;88:841-851.

20. ICF Research Branch of WHO CC F IC (DIMDI), Institute for Health and Rehabilitation Sciences, Ludwig-Maximilian University. ICF Core Sets multicenter international validation study. Ludwig-Maximilian University, Germany; 2006. Electronic Citation. http://www.icf-research-branch.org/research/ validationstudy.htm. Last accessed August 2009.

21. Barak S, Duncan P. Issues in selection outcome measures to assess functional recovery after stroke. NeuroRx 2006;3:505-524.

22. Duncan P, Goldstein L, Horner R, Landsman P, Samsa G, Matchar D. Similar motor recovery of upper and lower extremities after stroke. Stroke 1994;25:1181-1188.

23. Jorgensen $H$, Nakayama $H$, Raaschou H, Vive-Larsen J, Stoier $\mathrm{M}$, Olsen T. Outcome and time course of recovery in stroke. Part II: time course of recovery. The Copenhagen Stroke Study. Arch Phys Med Rehabil 1995;76:406-412.

24. Kwakkel G, Kollen B, Twisk J. Impact of time on improvement of outcome after stroke. Stroke 2006;37:2348-2353.

25. Verheyden G, Nieuwboer A, De Wit L, Thijs V, Dobbelaere J, Devos H, Severijns D, Vanbeveren S, De Weerdt W. Time course of trunk, arm, leg, and functional recovery after ischemic stroke. J Neurol Rehabil 2008;22:173-179.

26. Geyh S, Kurt T, Brockow T, Cieza A, Ewert T, Omar Z, Resch KL. Identifying the concepts contained in the outcome measures of clinical trials on stroke using the International Classification of Functioning, Disability and Health as a reference. J Rehabil Med 2004; (Suppl 44):56-62.

27. Uyttenboogaart M, Luijckx G, Vroomen P, Stewart R, De Keyser J. Measuring disability in stroke: relationship between the modified Rankin scale and the Barthel index. J Neurol 2007;254:1113-1117.

28. Algurén B, Lundgren-Nilsson A, Sunnerhagen K. Facilitators and barriers of stroke survivors in the early post-stroke phase. Disabil Rehabil 2009;18:1-8.

29. World Health Organization. Stroke. Recommendations on stroke prevention, diagnosis, and therapy. Report of the WHO Task Force on stroke and other cerebrovascular disorders. Stroke 1989;20:1407-1431.

30. Stier-Jamer M, Grill E, Ewert T, Bartholomeyczik S, Finger M, Mokrusch T, Kostanjsek N, Stucki G. ICF core set for patients with neurological conditions in early post-acute rehabilitation facilities. Disabil Rehabil 2005;27:389-395.

31. Lai SM, Duncan PW. Stroke recovery profile and the modified Rankin Assessment. Neuroepidemiology 2001;20:26-30.

32. Wilson J, Hareendran A, Hendry A, Potter J, Bone I, Muir K. Reliability of the modified Rankin Scale across multiple raters: benefits of a structured interview. Stroke 2005;36:777-781.

33. Sulter G, Steen C, De Keyser J. Use of the Barthel Index and modified Rankin Scale in acute stroke trials. Stroke 1999;30: 1538-1541.

34. Chakravarti I, Laha R, Roy J. Handbook of methods of applied statistics. Vol. 1. New York: Wiley; 1967. pp 392-394.
35. Bonita R, Beaglehole R. Recovery of motor function after stroke. Stroke 1988;19:1497-1500.

36. Hendricks $H$, van Limbek J, Geurts A, Zwarts M. Motor recovery after stroke: a systematic review of the literature. Arch Phys Med Rehabil 2002;83:1629-1637.

37. MacKay-Lyons M, Makrides L. Exercise capacity early after stroke. Arch Phys Med Rehabil 2002;83:1697-1702.

38. Potempa K, Lopez M, Braun L, Szidon P, Fogg L, Tinckell T. Physiological outcomes of aerobic exercise training in hemiparetic stroke patients. Stroke 1995;26:101-105.

39. Morris S, Dodd K, Morris M. Outcomes of progressive resistance strength training following stroke: a systematic review. Clin Rehabil 2004;18:27-39.

40. Glader E, Stegmayr B, Asplund K. Poststroke fatigue: a 2-year follow-up study of stroke patients in Sweden. Stroke 2002;33: 1327-1333.

41. Ingles J, Eskes G, Phillips S. Fatigue after stroke. Arch Phys Med Rehabil 1999;80:173-178.

42. Glader E, Stegmayr B, Norrving B, Terént A, Hulter-Åsberg K, Wester PO, Asplund K; Riks-Stroke Collaboration. Sex differences in management and outcome after stroke: a Swedish national perspective. Stroke 2003;34:1970-1975.

43. Nationella riktlinjer för strokesjukvård. Stockholm: Socialstyrelsen; 2006. Electronic Citation. http://www.socialstyrelsen.se/ Publicerat/2009/10295/2009-126-35.htm. Last accessed August 2009.

44. American Heart Association. Heart and Stroke Statistical 2008 update. Dallas, Texas: American Heart Association; 2008.

45. Hallström B, Jönsson A, Nerbrand C, Norrving B, Lindgren A. Stroke incidence and survival in the beginning of the $21 \mathrm{st}$ century in Southern Sweden. Stroke 2008;39:10-15.

46. Jorgensen H, Nakayama H, Raaschou H, Vive-Larsen J, Stoier $\mathrm{M}$, Olsen T. Outcome and time course of recovery in stroke. Part I: outcome. The Copenhagen Stroke Study. Arch Phys Med Rehabil 1995;76:399-405.

47. Lai S-M, Duncan PW, Dew P, Keighley J. Sex differences in stroke recovery. Prev Chronic Dis. Internet 2005. Electronic Citation. http://www.cdc.gov/pcd/issues/2005/jul/04_0137.htm. Last accessed July, 2005.

48. Barrett J. Bladder and bowel problems after stroke. Rev Clin Gerontol 2002;12:253-267.

49. Barnes M, Dobkin B, Bogousslavsky J. Recovery after stroke. New York: Cambridge University Press; 2005.

50. Jorgensen HS, Nakayama H, Moller Pedersen P, Kammersgaard L, Raaschou HO, Skyhoj Olsen T. Epidemiology of stroke-related disability. The Copenhagen Stroke Study. Clin Geriatr Med 1999;15:785-799.

51. Schepers V, Ketelaar M, van de Port I, Visser-Meily J, Lindeman E. Comparing contents of functional outcome measures in stroke rehabilitation using the International Classification of Functioning, Disability and Health. Disabil Rehabil 2007;29:221-230.

52. Flansbjer U, Downham D, Lexell J. Knee muscle strength, gait performance, and perceived participation after stroke. Arch Phys Med Rehabil 2006;87:974-980.

53. Rijntjes M. Mechanisms of recovery in stroke patients with hemiparesis of aphasia: new insights, old questions and the meaning of therapies. Curr Opin Neurol 2006;19:76-83.

54. Studenski S, Wallace D, Duncan P, Rymer M, Lai S. Predicting stroke recovery: three- and six- months rates of patient-centered functional outcomes based on the Orpington Prognostic Scale. J Am Geriatr Soc 2001;49:308-312.

55. Kwakkel G, Kollen B, Lindeman E. Understanding the pattern of functional recovery after stroke: facts and theories. Restor Neurol Neurosci 2004;22:281-299.

56. Levin $\mathrm{M}$, Kleim J, Wolf S. What do motor 'recovery' and 'compensation' mean in patients following stroke? Neurorehabil Neural Repair 2009;23:313-319. 